\title{
EFFECTS OF NON-IDEALITIES OF OP-AMPS ON ACTIVE FILTERS: AN ANALYTICAL STUDY
}

\author{
PREM BHUSHAN MITAL \\ Department of Electronics and Communication Engg., CRSCE, Murthal Sonepat-131039 (India) \\ UMESH KUMAR \\ Department of Electrical Engineering, I.I.T., New Delhi-110016, India \\ (Received May 15, 1994; in final form June 21, 1994)
}

This paper studies the effect of non-idealities of OP AMPs on the performance of active filters. The non-ideality is considered in terms of finite gain, finite gain-bandwidth product, slew-rate, and offset voltages. The effect of these non-idealities on active RC \& switched capacitor filters is highlighted. Some ways of reduction of these effects are also suggested and relative advantages and disadvantages of various compensation techniques are discussed.

\section{INTRODUCTION}

Ideal OP AMP $(O A)$

An ideal OA has the following characteristics:

1. It has infinite input impedance

2. Output impedance is zero and output voltage is independent of the current drawn from the output terminal.

3. Gain is infinite

4. If input voltage $V_{1}$ is zero, than output voltage $V_{0}$ is also zero.

5. It has infinite bandwidth.

6. Characteristics do not drift with temperature.

\section{Practical $O A$}

In practical OAs, all the infinite parameters and zero parameters specified above, have finite values. The equivalent circuits of an ideal and non-ideal OA are shown in Fig. 1.1.

The various other parameters of practical OAs are:

1. Finite gain $\left(A_{d}\right)$ with differential input and common mode gain $\left(A_{c}\right)$. Thus, the common mode rejection ratio $C M R R=\left|A_{d} / A_{c}\right|$ will be finite. Large values of CMRR are desired. For an ideal OA, CMRR is infinite.

2. Finite Bandwidth: Gain drops regularly with increasing frequency.

3. Slew-rate: Slew rate limitations arise because the transistors inside the OA are 


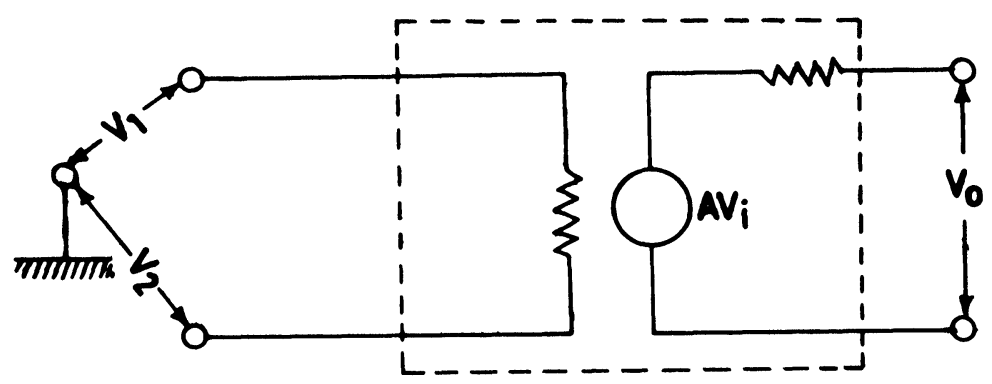

IDEAL OA

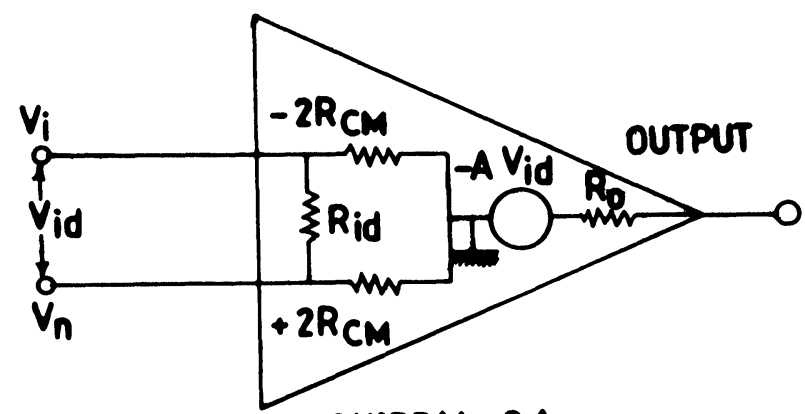

MONIDEAL OA

FIGURE 1.1

unable to provide sufficient current to rapidly charge capacitive loads. The slewrate also depends on the external circuitary connected to the OA. Usually, the worst case occurs when the OA is connected as a unity gain amplifier.

4. Input bias current is finite.

5. Input offset current is finite.

\section{Effect on Active RC Filters}

Desirable features of active RC filters are independent control of pole- $Q$ and $\omega_{p}$ (pole), dependence of $\omega_{\mathrm{p}}$ on passive elements only, realization of high-Q without requiring excessive amplifier gain, and insensitivity to the OP AMP gain-bandwidth product $[1,2]$.

Basic components in the design of an $-\mathrm{RC}$-active filter are inverting and noninverting amplifiers, integrators, and biquads. The effect of non-ideality, especially of GB and $\omega_{0}$, on these components is considered, as well as the effect of these finite parameters on various RC-active filters. Finally, effect of slew-rate is considered.

\section{Inverting and Non-Inverting Amplifiers}

The configuration of the circuit is shown in Fig. 1.2. The resistors $R_{i} \& R_{f}$ determine the closed loop gain of the amplifier. The resistor $R_{h}$ is introduced to minimize the 


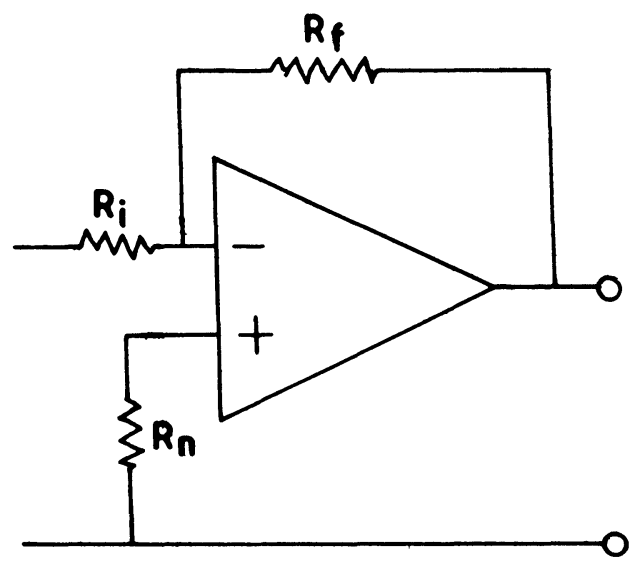

INVERTING AMPLIFIER

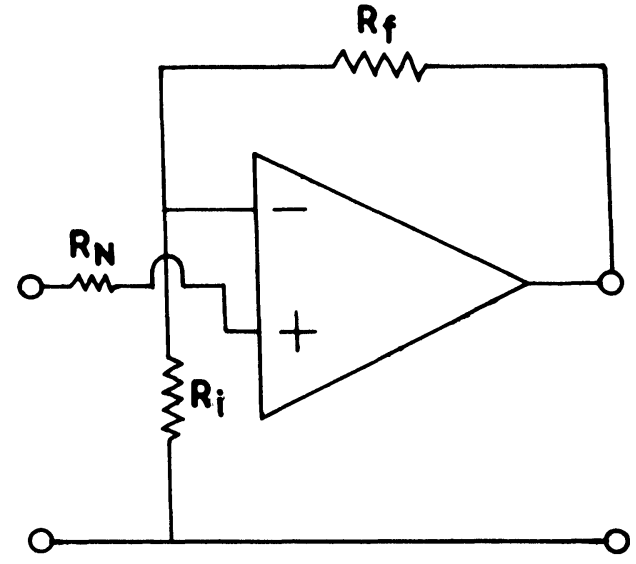

NON - MVERTING AMPLIFIER

FIGURE 1.2

effect of input bias current, its value being equal to the parallel combination of all the resistors connected to the inverting input.

The way of calculating the effect is shown only

$\mathrm{V}_{\mathrm{f}}=0$ (no current)

$\mathrm{V}_{\mathrm{iA}}=-\mathrm{E}_{\mathrm{o}}$ or $\mathrm{V}_{\mathrm{i}}=-\mathrm{E}_{\mathrm{o}} / \mathrm{A}$

$\frac{E_{i}-V_{i}}{R_{I}}=\frac{V_{i}-E_{o}}{R_{F}}$ or $\frac{E_{i} E_{o} / A}{R_{I}}=\frac{-E_{o} / A-E_{o}}{R_{F}}$

or $\frac{-E_{i}}{R_{I}}=E_{o} / A R_{F}+\frac{E_{o}}{R_{F}}+E_{o} / A R_{I}=\frac{E_{o}}{A R_{F} R_{I}}\left[R_{I}+R_{F}+A R_{I}\right]$

or $-E_{i} / R_{2}=E_{o} / A \frac{R_{I}+R_{F}}{R F R_{I}}\left[1+\frac{A R_{I}}{R_{I}+R_{F}}\right]=\frac{E_{o}}{\beta A R_{F}}[1+A \beta]$

$\therefore \mathrm{E}_{\mathrm{o}} / \mathrm{E}_{\mathrm{i}}=\mathrm{R}_{\mathrm{F}} / \mathrm{R}_{\mathrm{I}} \frac{\mathrm{A} \boldsymbol{\beta}}{1+\mathrm{A} \beta}=\alpha_{\mathrm{I}} \frac{\mathrm{A} \beta}{1+\mathrm{A} \beta}$

where $\alpha_{\mathrm{I}}=\mathrm{R}_{\mathrm{F}} / \mathrm{R}_{\mathrm{I}} \& \beta=\mathrm{R}_{\mathrm{I}} /\left(\mathrm{RF}+\mathrm{R}_{\mathrm{I}}\right)$

Close loop gain can be expressed as

$\mathrm{K}_{\mathrm{I}}=\alpha_{1} \frac{\mathrm{A}_{\mathrm{o}} \beta \omega_{\mathrm{o}}}{\mathrm{S}+\left(1+\mathrm{A}_{\mathrm{o}} \beta\right) \omega_{\mathrm{o}}}$

It is clear that the above closed-loop gain has a pole at

$\mathrm{O}_{\mathrm{I}}=-\left(1+\mathrm{A}_{\mathrm{o}} \beta\right) \omega_{\mathrm{o}}=-\left(1+\frac{\mathrm{A}_{\mathrm{o}}}{1-\alpha_{\mathrm{I}}}\right) \omega_{\mathrm{o}}$ 
Closed-loop Input Impedance for the inverting mode could be written as

$\mathrm{Z}_{\mathrm{i} 1}=\mathrm{R}_{1}+\mathrm{R}_{\mathrm{F}} / 1+\mathrm{A}$

Substituting gain - dependent value of $A$,

$Z_{i 1}=R_{1}+R_{F} / 1+\frac{A_{0} \omega_{0}}{S+\omega_{0}}=\frac{R_{1}}{\beta}\left[\frac{S+\left(1+A_{0} \beta\right) \omega_{0}}{S+\left(1+A_{o}\right) \omega_{0}}\right]$

or $Z_{i 1}=R_{1}+R_{i s}+\frac{\left(R_{i p}\right)\left(S L_{i}\right)}{R_{i p}+S L_{i}}$

where $R_{\text {is }}=R_{F} / A_{o}+1, R_{i p}=\frac{R_{F} A_{o}}{A_{o}+1} \& L_{i}=R_{F} A_{o} /\left(A_{o} \omega_{o}\right)^{2} \omega_{o}$

for $A_{o} \gg 1$

It is seen that the input impedance $Z_{i 2}$ is resistive and its value is $R_{1}$ for frequencies much less than $A_{0} \beta \omega_{0}$. For frequencies between $A_{0} \beta \omega_{0}$ and $A_{0} \omega_{0}, Z_{i 3}$ is predominantly inductive. For frequencies above $A_{0} \omega_{0}, Z_{i 1}=R_{I}+R_{F}$.

The effect of this inductive loading on the previous stage may become considerable in some cases. However, for low-closed loop gain, $Z_{i 1}$ is essentially resistive for the useful frequency range.

The expression for the output impedance $\mathrm{Z}_{\mathrm{o}}$ can be similarly derived and is given by

$Z_{o}=\frac{R_{o}}{1+A_{o} \beta}=R_{o s}+\frac{R_{o p} L_{o} S}{R_{o p}+L_{o} S}$

where $\mathrm{R}_{\mathrm{os}}=\mathrm{R}_{\mathrm{o}} / 1+\mathrm{A}_{\mathrm{o}} \beta, \mathrm{R}_{\mathrm{op}}=\mathrm{R}_{\mathrm{o}} \mathrm{A}_{\mathrm{o}} \beta /\left(1+\mathrm{A}_{\mathrm{o}} \beta\right) \& \mathrm{~L}_{\mathrm{o}}$

$$
=\mathrm{R}_{\mathrm{o}}=\left\{\left(1+\mathrm{A}_{\mathrm{o}} \beta\right) \omega_{\mathrm{o}}\right\}
$$

Thus, $Z_{o}$ represents a small resistance $R_{o s}$ in series with the parallel combination of inductance $L_{o}$ and resistance $R_{o p}$. The output impedance is predominantly inductive for the normal useful frequency range of the amplifier, i.e., between $\omega_{0} \&$ $A_{o} \beta \omega_{0}$.

In active RC-realization using more than one OA such as biquad, the effect of the output impedance will be to add additional poles and zeroes, thus affecting the performance of the filter.

Similar expressions can also be derived for non-inverting amplifiers.

It is seen that for the same ideal gain, i.e., $\left|\alpha_{\mathrm{I}}\right|=\left|\alpha_{\mathrm{N}}\right|=\alpha$, the bandwidth of the inverting mode is less than that of non-inverting mode, the ratio being $2 / 1+$ $\alpha$. In particular, for unity gain, the bandwidth for the inverting mode is only half that of the non-inverting mode.

\section{Integrators}

Specifically, if the OA frequency response is taken into account, the transfer function of an integrator circuit may be expressed as

$T(j w)=1 / R(\omega)+j X(\omega)$ 
Then, the integrator Q-factor is defined as

$\mathrm{Q}_{1}=\mathrm{X}(\omega) / \mathrm{R}(\omega)$

The basic circuit for an inverting integrator is shown in Fig. 1.3.

$$
V_{0} / V_{i}=-\frac{A}{(A+1) S C R+1}
$$

when $A$ is replaced by $A_{0} \omega_{0} / S \omega_{0}$ and then substituting $S$ by jw, we have

$\mathrm{Q}_{1}=\frac{\omega\left[\left(\mathrm{A}_{\mathrm{o}}+1\right) \omega_{\mathrm{o}} \mathrm{CR}+1\right]}{\omega_{\mathrm{o}}-\omega^{2} \mathrm{CR}}$

Assuming $\omega_{0} \ll \omega \ll A_{0} \omega_{0}$, we have

$\mathrm{Q}_{1} \cong \frac{\omega \mathrm{A}_{\mathrm{o}} \omega_{\mathrm{o}} \mathrm{CR}}{-\omega^{2} \mathrm{CR}}=-\mathrm{A}_{\mathrm{o}} \omega_{\mathrm{o}} / \omega=-|\mathrm{A}(\mathrm{jw})|$

Thus, for an inverting integrator $Q_{1}=-|A|$

Similarly, for a non-inverting integrator, $Q_{I}=(-|A| / 3)$.

It is to be noted that for an ideal OA used in integrators, the real part in equation 1.3 would be zero and, hence, $Q_{I}$ for such integrator will be infinite. Thus, the effect of finite GB is to make the integrator lossy..

\section{Biquadratic Filter Section}

This type of filter can be realized by a two section loop as shown in the Fig. 1.4 The transfer function is

$$
\begin{aligned}
\frac{\mathrm{V}_{\mathrm{o}}}{\mathrm{V}_{\mathrm{i}}} & =\frac{-\mathrm{s} \omega_{\mathrm{o}}}{\mathrm{S}^{2}+\left(\frac{\omega_{\mathrm{p}}}{\mathrm{Q}}\right) \mathrm{S}+\omega_{p}^{2}} \text { where } \omega_{\mathrm{p}}=1 / \tau \\
\tau & =\mathrm{RC} \\
\mathrm{Q}_{\mathrm{k}} & =\frac{\mathrm{Q}}{1-(4 \mathrm{Q} /|\mathrm{A}|)}
\end{aligned}
$$

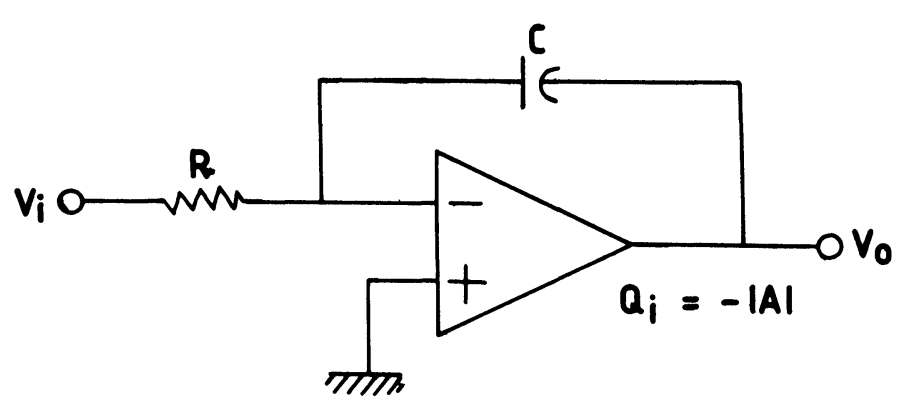

FIGURE 1.3 


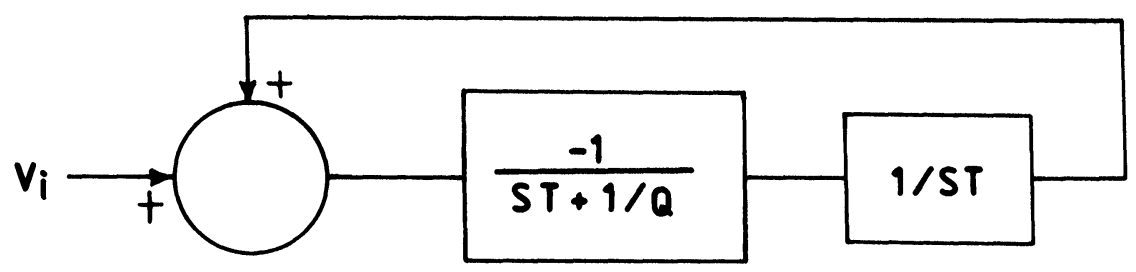

FIGURE 1.4(a)

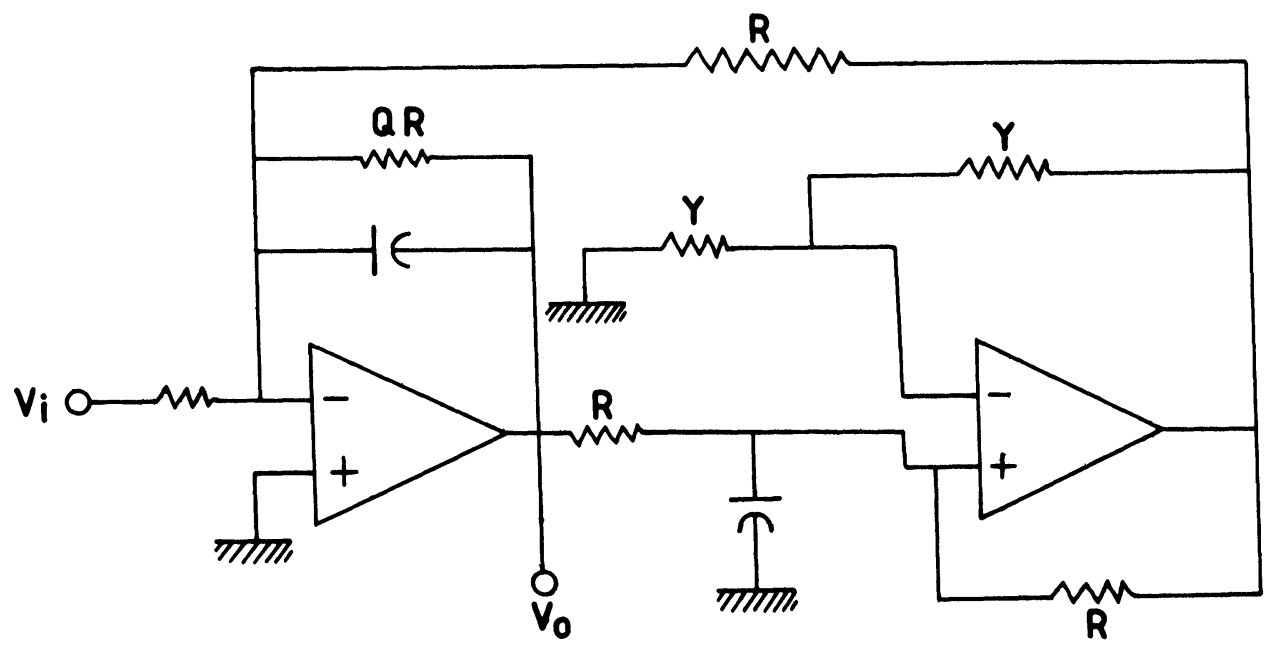

FIGURE 1.4(b)

It should be noted that $Q$ is nominal value of $Q$, and $Q_{k}=Q$ if $A$ is infinite. Similarly, realized value of pole-frequency $\omega_{\mathrm{p}} \mathrm{k}$ can be given by

$$
\begin{aligned}
& \mathrm{W}_{\mathrm{pk}}=\mathrm{W}_{\mathrm{p}} 1+1 / \mathrm{Q}_{2}\left(\frac{1}{\mathrm{Q}}+\frac{1}{\mathrm{Q}_{2}}\right) \\
& \text { and } \mathrm{Q}_{\mathrm{k}}=\frac{1}{\frac{1}{\mathrm{Q}_{2}}+\frac{1}{\mathrm{Q}_{1}}+\frac{1}{\mathrm{Q}_{2}}}
\end{aligned}
$$

where $Q_{1} \& Q_{2}$ are the Q-factor of two integrators in Fig. 1.4(a). For the circuit of Fig. 1.4b

$$
\begin{aligned}
& \omega_{\mathrm{pk}}=\omega_{\mathrm{p}} 1+3 /|\mathrm{A}|^{2}-3 /|\mathrm{A}| \mathrm{Q} \\
& \omega_{\mathrm{pk}}=\omega_{\mathrm{p}} 1+3 /|\mathbf{A}|^{2}-3 /|\mathrm{A}| \mathrm{Q}
\end{aligned}
$$

Thus, in this circuit of biquadratic filter section, the value of $Q_{k}$ increases and that of $\omega_{\mathrm{pk}}$ decreases compared to the nominal values. The values of $Q_{k}$ and $\omega_{\mathrm{pk}}$ 
R 3

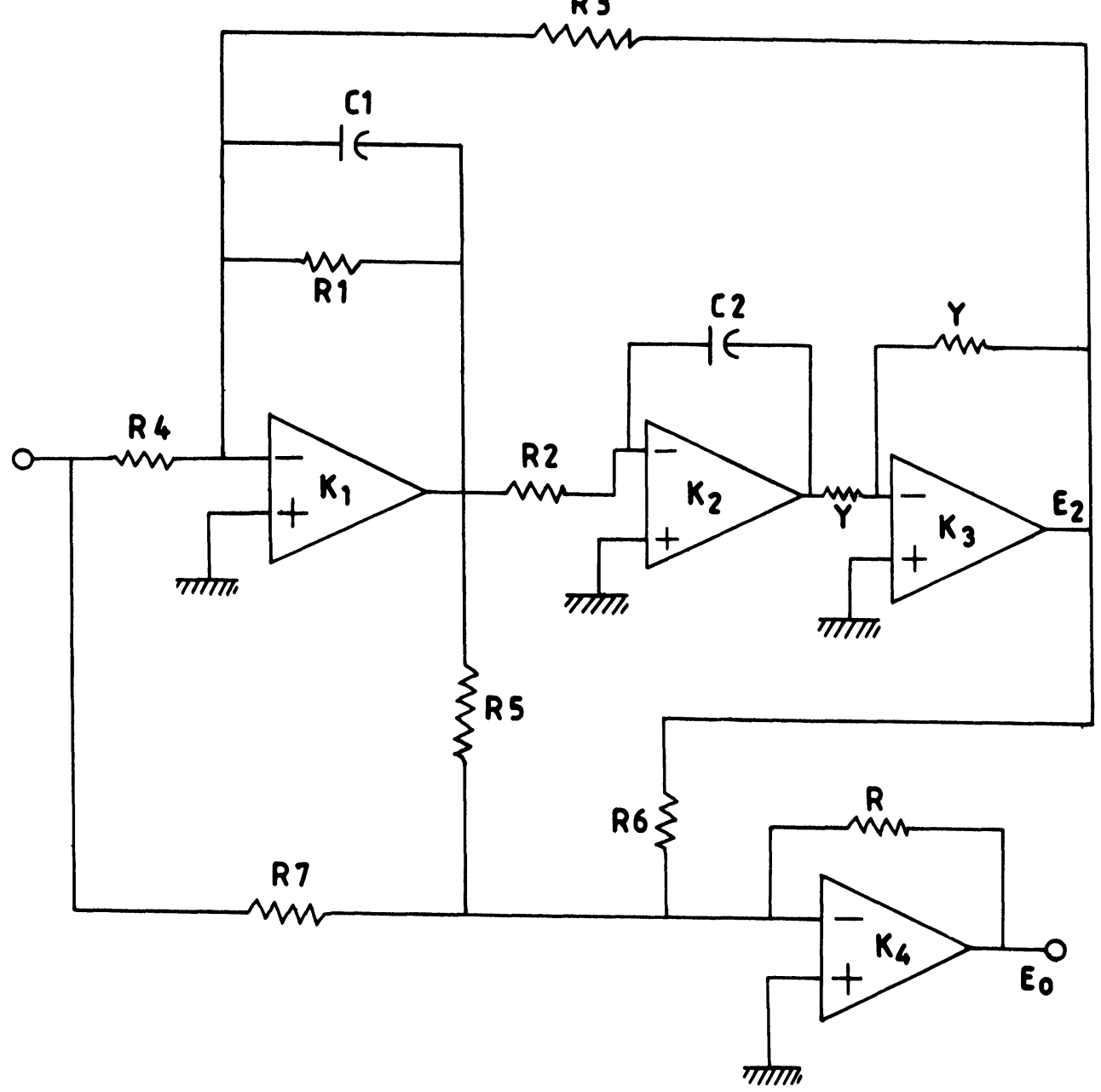

FIGURE 1.5

for values of $|\mathrm{A}|, \mathrm{Q}$, and $\omega_{\mathrm{p}}$ are also calculated. A more general biquadratic circuit was given by Thomas. This is shown in Fig. 1.5.

The transfer function

$\mathrm{E}_{\mathrm{o}} / \mathrm{E}_{1}=\frac{\omega\left(\mathrm{s}^{2}+\frac{\omega_{\mathrm{z}}}{\mathrm{Q}_{\mathrm{z}}} \mathrm{s}+\omega_{\mathrm{z}}^{2}\right)}{\mathrm{S}^{2}+\omega_{\mathrm{p}} / \mathrm{Q}_{\mathrm{p}}^{5}+\omega_{\mathrm{p}}^{2}}$

where $\omega_{z} \& \omega_{\mathrm{p}}$ are related to the frequencies at which the loss peaks and transmission poles occur. Such basic building blocks can be cascaded to form transfer functions of order higher than 2 . 
If we consider a finite gain infinite bandwidth $O A$, then realized $Q_{p} \rightarrow$

$\mathrm{Q}_{\mathrm{pk}}=\mathrm{Q}_{\mathrm{p}} / 1+2 \mathrm{Q}_{\mathrm{p}} / \mathrm{A}_{\mathrm{o}}$

But, if the bandwidth is considered finite, then

$Q_{p k}=\frac{Q_{p}}{1+\frac{2 Q_{p}}{A_{o} \omega_{o}}\left(\omega_{o}-2 \omega_{p}\right)}$

The actual $Q_{p}$ increases at high resonant frequency because of finite gain and bandwidth in a non-ideal OA.

After remaining constant over a broad band, the $Q_{p k}$ begins to increase and then becomes infinite. Such an increase in $Q_{p k}$ is called $Q_{p k}$ enhancement.

\section{ANALYSIS PROCEDURE FOR A GENERAL ACTIVE RC-FILTER}

To find the effect of non-idealities of OA on the transfer function of a filter, we replace the ideal OA by a finite gain OA of gain $\mathrm{A}$, and on this basis derive the new transfer function. Now, replacing $A$ by $A_{0} \omega_{0} / S+\omega_{0}$ gives the total effect of $\mathrm{OA}$ finite $\mathrm{G} B$ on filter. Thus, a generalized procedure can be written as:

1. Identify all nodes in the filter circuit and number them. Number output node as $\mathrm{V}_{\mathrm{o}}$.

2. For all such nodes that are not the output of $\mathrm{OA}_{\mathrm{s}}$, write the KCL. No equation should be written at output node. The admittance matrix can be directly made for such nodes.

3. Write gain equations for $\mathrm{OA}$ in the circuit, and include these equations at proper places in the admittance matrix. Thus, the resulting matrix would be as:

$[\mathrm{Y}][\mathrm{V}]=[\mathrm{I}]_{\text {Current matrix. }}$

4. Solve the above matrix equation for only $\mathrm{V}_{\mathrm{o}} ; \mathrm{V}_{\mathrm{o}}$ can be obtained by the determinant equation $\mathrm{V}_{\mathrm{o}}=\Delta_{\mathrm{k}} / \Delta$ where $\Delta$ is $|\mathrm{Y}|$ and $\Delta_{\mathrm{k}}$ is $|\mathrm{Y}|$ when its kth column is replaced by [I] if $\mathrm{V}_{\mathrm{o}}$ appears in kth row in [V].

5. From the above equation, a new transfer function $V_{0} / V_{i}$ can be found. Replace OA gain $A_{i}$ by $A_{o i} \omega_{0 i} /\left(s+\omega_{o i}\right)$ or $A_{o i} \omega_{o i} / S$ whatever model is recognized.

6. A higher order transfer function will result. On factoring it and then rejecting the poles lying much away from the dominant poles, we compare the above equation with that of an ideal $\mathrm{OA}$. 
7.' As a result of this comparison, deviations in the values of $Q_{p}$ and $\omega_{p}$ can be seen.

It is to be noted that procedures up to step (5) can be implemented on a computer. The result will not be in the form of an expression, but a plot of the curve will result, considering the effect of non-ideality. Thus, this would be the plot of actual performance of the filter.

For considering ideal performance:

1. Both the inputs of the OAs are labeled as nodes with the same voltage. However, equations for each node should be written separately. Now the gain equation need not be written.

2. The resulting admittance matrix will not be a function of OA gain $\mathrm{A}$. The transfer function of a filter with ideal $\mathrm{OA}$ can thus be plotted, and resulting plots can be compared.

\section{Effect of Slew Rate}

Slew rate, which is the time rate of change of the closed loop amplifier output voltage under large signal conditions, can cause serious degradation of the filter frequency response, sometimes leading to instability.

When an OA is overdriven by a large input signal, the output slews. It has been found that while magnitude distortion occurs in both the closed loop modes, phase distortion only occurs under closed-loop conditions. Slew-induced distortion for the low gain inverter configuration is much larger than for the inverting integrator.

If a sinusoidal input causes the output to have a maximum slope greater than the slew rate of the amplifier, the output will suffer distortion. The slew-induced distortion (SID) causes an additional phase-shift (lag) and an attenuation of the fundamental component of the signal at the output. The distortion is not present at lower amplitude or lower frequency [3].

\section{ANALYSIS OF SLEW INDUCED DISTORTION}

A previously used method for analyzing the effect of slew rate was a non-linear system modeling technique based on a describing function method. A similar technique based on Fourier analysis was also applied to develop a non-linear macro model of the OA.

If an OA is operating in the range of the SID, then its modeling using a Volterra series is quite difficult if exact methods are utilized. Thus, a distortion generator method is used here. This method provides a sufficient accuracy of estimation for small non-linear distortions. 
The Volterra model for a non-linear system could be represented by the model shown:

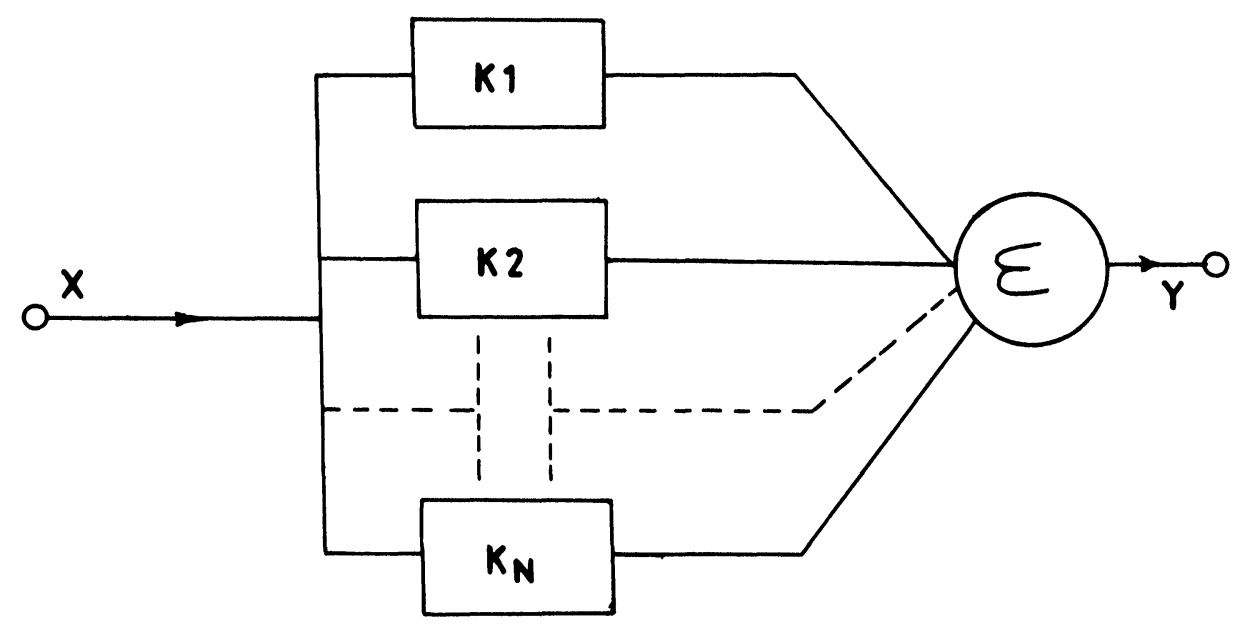

FIGURE 1.6

The non-linear system is decomposed to a linear system and a finite number of homogeneous non-linear subsystems that are completely characterized by their nonlinear transfer function. In a mathematical notation such as Laplace Transform, we have

$\mathrm{Y}\left(\mathrm{S}_{1}, \mathrm{~S}_{2} \ldots \mathrm{S}_{\mathrm{n}}\right)=\sum_{\mathrm{k}=1}^{\mathrm{n}} \mathrm{k}\left(\mathrm{S}_{1}, \mathrm{~S}_{2} \ldots \mathrm{S}_{\mathrm{k}}\right) \prod_{\mathrm{j}=1}^{\mathrm{k}} \times\left(\mathrm{S}_{\mathrm{j}}\right)$

Here, kernels up to nth order have been utilized to represent the system. Physical interpretation of $K\left(S_{1}, S_{2} \ldots S_{n}\right)$ can be given as follows: $n$ sinusoidal signals of complex frequency $S_{1}, S_{2}, \ldots S_{n}$ of unit amplitude of $n$th order produce a signal at frequency $\left(S_{1}+S_{2}+\ldots S_{n}\right)$.

The relation between input $\left(\mathrm{V}_{\mathrm{i}}\right)$ \& output $\left(\mathrm{V}_{\mathrm{o}}\right)$ of an OA possessing non-linear and inertial properties using eqn. 1.5 is

$\mathrm{V}_{\mathrm{o}}\left(\mathrm{S}_{1}, \mathrm{~S}_{2}, \ldots \mathrm{S}_{\mathrm{n}}\right)=\sum_{\mathrm{k}=1}^{\mathrm{n}} \mathrm{K}\left(\mathrm{S}_{1}, \mathrm{~S}_{2}, \ldots \mathrm{S}_{\mathrm{n}}\right) \prod_{\mathrm{j}=1}^{\mathrm{k}} \mathrm{V}_{\mathrm{i}}\left(\mathrm{S}_{\mathrm{j}}\right)$

where the first component represents the linear portion. Thus, OA can be represented as a linear voltage-controlled voltage source with transfer coefficient $\left(K\left(S_{1}\right)\right.$ and a distortion generation $\epsilon\left(S_{1}, S_{2} \ldots S_{n}\right)$ at the output as shown in Fig. 1.7.

For better accuracy, a differential OA model should be used. DOA is regarded as a VCVS with the added elements that indicate the finiteness of the input and output impedances. The model is shown in Figure 1.8. The DOA kernels obtained 


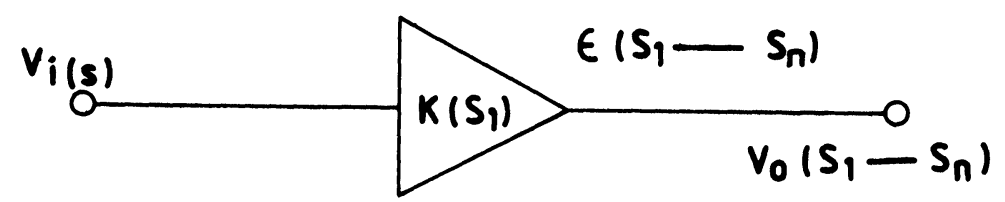

FIGURE 1.7

by this method are given below:

$$
\begin{aligned}
& \mathrm{K}_{\mathrm{oA}}\left(\mathrm{S}_{1}\right)=\frac{\mathrm{a}_{1}}{1+\mathrm{S}_{1} \mathrm{~T}_{\mathrm{oA}}} \\
& \mathrm{K}_{\mathrm{oA}}\left(\mathrm{S}_{1}, \mathrm{~S}_{2}\right)=\frac{\mathrm{a}_{2}}{\left(1+\mathrm{S}_{1} \mathrm{~T}_{\mathrm{oA}}\right)\left(1+\mathrm{S}_{2} \mathrm{~T}_{\mathrm{oA}}\right)}=0 \\
& \mathrm{~K}_{\mathrm{oA}}\left(\mathrm{S}_{1}, \mathrm{~S}_{2}, \mathrm{~S}_{3}\right)=\frac{\mathrm{a}_{3}}{\prod_{\mathrm{j}=1}^{3}\left(1+\mathrm{S}_{\mathrm{j}} \mathrm{T}_{\mathrm{oA}}\right)}
\end{aligned}
$$

\section{ANALYSIS PROCEDURE}

The analysis procedure for any active filter adopted is as follows:

(i) Identify various nodes of circuits and draw a signal flow graph in such a way that its every node represents a voltage. If elements are given in the form of impedances, convert them into admittances.

(ii) Find the gain of every branch of the signal flow graph.

(iii) Find the voltage at VCVS input $\mathrm{V}_{\mathrm{i}}(\mathrm{s})$

(iv) Find the output voltage of the device excluding the distortion generators

(v) Find the parameters of the distortion generator.

(vi) Find the total output signal.

(vii) Assuming the circuit to be linear, recompute the parameters of the distortion generators at the circuit output.

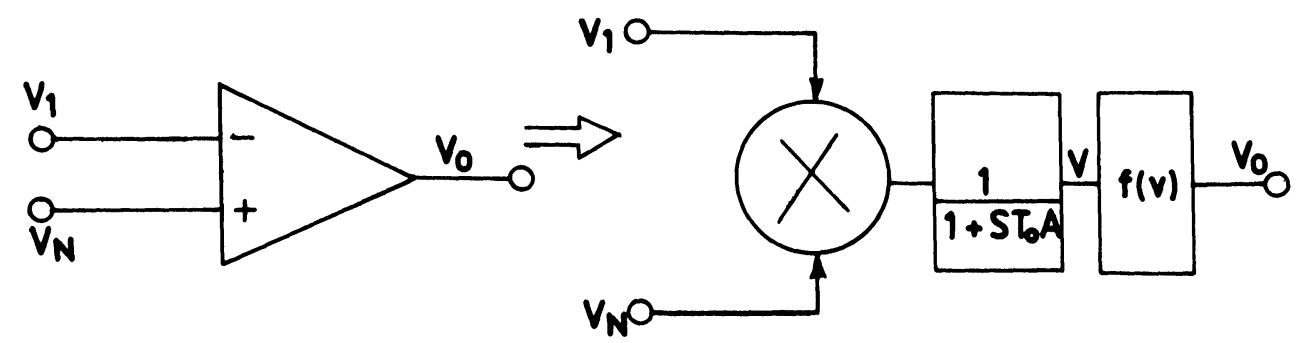


(viii) From an analysis of the expression describing the filter output signal, kernels of the function of the Volterra series are determined. This series shows the relation between input and output signals. These expressions are:

$$
\begin{aligned}
& \mathrm{K}_{\mathrm{f}}\left(\mathrm{S}_{\mathrm{f}}\right)=\mathrm{T}_{\mathrm{f}}\left(\mathrm{S}_{1}\right) \\
& \mathrm{K}_{\mathrm{f}}\left(\mathrm{S}_{1}, \mathrm{~S}_{2}, \ldots \mathrm{S}_{\mathrm{p}}\right)=\mathrm{K}_{\mathrm{oA}}\left(\mathrm{S}_{1}, \mathrm{~S}_{2} \ldots \mathrm{S}_{\mathrm{p}}\right)(-1)^{\mathrm{P}} \prod_{\mathrm{j}=1}^{\mathrm{P}}\left(\mathrm{T}_{13}\left(\mathrm{~S}_{\mathrm{j}}\right) \mathrm{T} \epsilon_{5}\left(\epsilon \mathrm{S}_{\mathrm{j}}\right)\right)
\end{aligned}
$$

Utilizing an expression for the amplitude of the first harmonic, we find the amplitude frequency response from the first harmonic

$$
\left[\mathrm{K}_{\mathrm{eq}}(\mathrm{iw})\right]=\left|\mathrm{k}_{\mathrm{f}}(\mathrm{iw})\right|+3 / 4 \mathrm{Um}^{2}\left|\mathrm{~K}_{\mathrm{f}}(\mathrm{iw}, \mathrm{iw})-\mathrm{iw}\right|
$$

The actual calculations for this bandpass filter are done using computer program.

\section{EFFECT ON SWITCHED CAPACITOR FILTERS}

Although many of the methods developed for active RC filters can be directly adopted to SC filters, this is not true for the analysis of the effects of the amplifier dynamics on the filter response. In the SC case, such an analysis is complicated by the fact that the amplifier dynamics are of a continuous time nature while discretetime methods have to be used in evaluating the filter transfer function [4-7].

\section{ANALYSIS PROCEDURE}

1. Write the differential equations governing the operation of each OA.

2. Obtain the solution of the differential equation and evaluation at $t=n T$, since the OA output voltage are continuous functions of time.

3. Use conservation of charge principles at switching intervals to write the equation to relate various voltages.

4. Take the Z-transform of the equation obtained in steps (2) \& (3) and solve simultaneously to obtain the solution.

\section{Effects of Finite Gain and $G B$}

The actual transfer function $\mathrm{H}_{\mathrm{a}}(\omega)$ of an integrated circuit can be given by

$$
H_{a}(\omega)=\frac{H_{i}(\omega)}{\left[1-M(\omega) e^{-j(\theta(\omega)}\right]}
$$

where $M(\omega)$ is the magnitude error and $\theta(\omega)$ is the phase error, $H_{i}(\omega)$ is the ideal transfer function, i.e., the transfer function of elements are considered to be the 
ideal. Furthermore, for small errors $M(\omega), \theta(\omega) \ll 1$, the above expression can be approximately equivalent to

$H_{\mathrm{a}}(\omega) \cong \frac{\mathrm{H}_{\mathrm{i}}(\omega)}{1-\mathrm{M}(\omega)-\mathrm{j} \theta(\omega)}$

This form is especially convenient for estimating the gain and phase errors of $\mathrm{SC}$ integrators and for evaluating the effects of these errors on the overall filter transfer function.

The effect on integrator and biquads have been studied [8].

INTEGRATORS: Assuming that the OA has a finite dc gain $\mathrm{A}_{0}$, it can be shown for the inverting integrator circuit that $M(w)=-1 / A_{o}\left(1+\left(C_{1} / 2 C_{2}\right)\right)$ and $\theta(w)$ $=\left(C_{1} / C_{2} / 2 A_{o} \tan (w T / 2)\right)$. For calculating the finite bandwidth effect in integrators, all the feeding capacitors (if they are more than one) should be summed to obtain an effective value of $\mathrm{C}_{1}$.

$B I Q U A D S$ : These circuits are formed by connecting an inverting integrator and a non-inverting integrator in a feedback loop. When these two integrators have magnitude errors $M_{1}(w)$ and $M_{2}(w)$ and assuming large $Q$-factors, it can be shown that the biquad pole frequency $\omega_{\mathrm{p}}$ undergoes a fractional change given by

$\frac{\Delta \omega_{\mathrm{p}}}{\omega_{\mathrm{p}}} \cong\left[\mathrm{M}_{1}\left(\omega_{\mathrm{o}}\right)+\mathrm{M}_{2}\left(\omega_{\mathrm{o}}\right)\right]$

Similarly, if the inverting and non-inverting integrators have phase errors $\theta_{1}(w)$ and $\theta_{2}(w)$, then the realized pole $Q$-factor, $Q_{p k}$ is related to nominal $Q_{p}$ by

$\mathrm{Q}_{\mathrm{pk}}=\frac{\mathrm{Q}_{\mathrm{p}}}{1+\mathrm{Q}_{\mathrm{p}}\left[\theta_{1}\left(\omega_{\mathrm{p}}\right)+\theta_{2}\left(\omega_{\mathrm{p}}\right)\right]}$

The change in the value of $\theta$ results in a change in the magnitude of the biquad transfer function $T(j \omega)$ at resonance given by

$\frac{\left|T\left(j \omega_{p k}\right)\right|}{\left|T_{a}\left(j \omega_{p}\right)\right|}=\frac{1}{1+Q\left[Q_{1}\left(\omega_{p}\right)+Q_{2}\left(\omega_{p}\right)\right]}$

When the OAs have both the finite gain and finite bandwidth, then simple calculus can be used to show that the total deviation is merely the sum of the deviations caused by the individual non-idealities.

If the clocking frequency $f_{c}$ is at most $1 / 5$ of the OA bandwidth $f_{t}$, the integrator phase and magnitude deviations, caused by the finite $f_{t}$, will be less than $0.04 \%$ for $C_{1}<C_{2}$. Thus, for $f_{c} / f_{t}<1 / 5$ the effects of the finite OA bandwidth are negligible. Thus, for given values of $f_{p}$ and $f_{t}$, one should use as low a value for $f_{c}$ as possible. The frequency deviation in the SC circuits is obviously much smaller than that of the corresponding active RC-circuits. 


\section{Detailed Generalized Analysis Procedure}

The analytical procedure for the analysis of a SC network is summarized below:

(i) Identify the subnetwork $\mathrm{NS}_{\mathrm{i}}(\mathrm{i}=1,2 \ldots)$ around each $\mathrm{OA}$ in the original SC network N.

(ii) Set up the charge conservation equations (CCE) for the OA input nodes for given phase (even or odd).

(iii) Identify the coefficient $\alpha_{1 \mathrm{qi}}, \alpha_{1 \mathrm{ai}}, \alpha_{2 \mathrm{qi}}, \alpha_{2 \mathrm{ai}} \ldots$, etc. in the CCE in terms of the ratios of capacitances in the circuit. For example, CCE may be

$\mathrm{V}_{\mathrm{p}}(\mathrm{t})=\alpha_{1 \mathrm{q}} \mathrm{V}_{\mathrm{q}}(\mathrm{t})+\alpha_{1 \mathrm{a}} \mathrm{V}_{\mathrm{a}}(\mathrm{t})+\beta_{1 \mathrm{q}} \mathrm{V}_{\mathrm{q} 1}+\beta_{1 \mathrm{a}} \mathrm{V}_{\mathrm{al}}+\beta_{1 \mathrm{P}} \mathrm{V}_{\mathrm{P} 1}$

(iv) Obtain the parameters $\lambda_{1 \mathrm{i}}, \lambda_{2 \mathrm{i}}, \ldots$ through $\mathrm{K}_{1 \mathrm{i}}, \mathrm{K}_{2 \mathrm{i}}$ using the equation

$\lambda_{\mathrm{j}}=\exp (-\mathrm{kj} . \mathrm{T} / 2) \& \mathrm{k}_{\mathrm{j}}=\alpha_{\mathrm{jq}} \mathrm{GB}+\omega_{\mathrm{o}} \mathrm{j}=1,2$,

where GB is the gain-bandwidth product and $\omega_{0}$ is the dominant pole of OA.

(v) Obtain the constraint equation for this given phase yielding the coefficients $\mathrm{A}_{\mathrm{qpi}}^{\mathrm{ee}}, \mathrm{A}_{\mathrm{qpi}}^{\mathrm{eo}}, \mathrm{B}_{\mathrm{api}}^{\mathrm{ee}}, \mathrm{B}_{\mathrm{api}}^{\mathrm{eo}} \ldots \ldots \ldots \mathrm{A}_{\mathrm{qpi}}^{\mathrm{oo}}, \mathrm{A}_{q p i}^{\mathrm{oe}}, \mathrm{B}_{\mathrm{qpi}}^{\mathrm{oo}}, \mathrm{B}_{q p i}^{\mathrm{oe}} \ldots \ldots$, etc.

The constraint equation can be written as:

$V_{p i}^{e}=A_{q p i}^{e e} V_{q i}^{e}+A_{q p i}^{e o} V_{q i}^{o}+B_{a p i}^{e e} V_{a i}^{e}+B_{a p i}^{e o} V_{a i}^{o}$

(vi) Obtain a passive part from the given SC network by removing all the OAs. From the Indefinite Admittance Matrix (IAM) of this passive network, obtain the Definite Admittance Matrix (DAM) after allowing for node contraction owing to switching and elimination of ground nodes.

(vii) Apply the constraints arrived as in step 5 to the DAM in step 6 to modify pertinent columns. Subsequently, eliminate the columns corresponding to the OA input nodes and discard the rows corresponding to the OA output nodes. This gives the final reduced DAM $\left(\mathrm{Y}_{\mathrm{F}}\right)$ of the active $\mathrm{SC}$ network. In case the input signal source is sampled and held, the coefficient in the constraint equations corresponding to the signal node voltage $V_{\text {in }}(z)$ shall be zero. Also, $Y_{F}$ can be reduced further by eliminating the column and the two corresponding to either the even or odd phase part of the input signal voltage.

(viii) Subject $\mathrm{Y}_{\mathrm{F}}$, obtained as above, to a standard matrix operation to obtain the desired network function.

\section{ILLUSTRATION OF THE METHOD}

Consider SC Integrator with the nodes numbered $\mathrm{a}_{1}, \mathrm{p}_{1}, \mathrm{q} .$. In the even phase, $[(n-1 / 2) T<t \leq n T]$, the CCE is

$$
\begin{aligned}
& C_{1}\left[V_{a}(t)-V_{p}(t)\right]-C_{1}\left[V_{a I}-V_{p I}\right]=C_{2}\left[V_{p}(t)-V_{q}(t)\right]-C_{2}\left[V_{P I}-V_{q I}\right] \\
& V_{p}(t)=\frac{C_{2}}{C_{1}+C_{2}} V_{q}(t)-\frac{C_{2}}{C_{1}+C_{2}} V_{q I}+V_{p I}
\end{aligned}
$$


Comparing this equation:

$\alpha_{1 \mathrm{q}}=\mathrm{C}_{2} / \mathrm{C}_{1}+\mathrm{C}_{2} ; \beta_{1 \mathrm{q}}=-\alpha_{1 \mathrm{q}} ; \alpha_{1 \mathrm{a}}=0=\beta_{1 \mathrm{a}} ; \beta_{1 \mathrm{P}}=1$

Assuming $\mathrm{A}(\mathrm{s})=\mathrm{GB} / \mathrm{S}$

$\mathrm{K}_{1}=\alpha_{1 \mathrm{q}} \mathrm{GB}=\frac{\mathrm{GB} \cdot \mathrm{C}_{2}}{\mathrm{C}_{1}+\mathrm{C}_{2}}$ and $\lambda_{1}=\exp \left[\frac{-\mathrm{GB} \mathrm{C}_{2}}{\mathrm{C}_{1}+\mathrm{C}_{2}} \cdot \mathrm{T} / 2\right]$

Therefore,

$A_{q p}^{e e}=-\left[\frac{C_{2}}{C_{1}+C_{2}} \exp \left(-\frac{G B \cdot C_{2}}{C_{1}+C_{2}} T / 2\right) /\left[1-\exp \left(-\frac{G_{B C}}{C_{1}+C_{2}} T / 2\right)\right]\right.$

$A_{\mathrm{qp}}^{\mathrm{eo}}=-\mathrm{Z}^{-1 / 2} \mathrm{~A}_{\mathrm{qp}}^{\mathrm{ee}} ; \beta_{\mathrm{qp}}^{\mathrm{ee}}=0=\beta_{\mathrm{ap}}^{\mathrm{eo}}$

Similarly, for the odd phase $[(n-1) T<t \leq(n-1 / 2) T]$ one has CCE

$C_{2}\left[V_{p}(t)-V_{q}(t)\right]=C_{2}\left[V_{p 1}-V_{q 1}\right]$

which leads to $\alpha_{2 q}=1, \beta_{2 q}=-1, \beta_{2 p}=1$

$$
\begin{aligned}
& \mathbf{A}_{\mathrm{qp}}^{\mathrm{oo}}=-[\exp (-\mathrm{GB} \cdot \mathrm{T} / 2)] /[1-\exp (-\mathrm{GB} \cdot \mathrm{T} / 2)] \\
& \mathbf{A}_{\mathrm{qp}}^{\mathrm{oe}}=-\mathbf{z}^{-1 / 2} \mathbf{A}_{\mathrm{qp}}^{\mathrm{oo}} \\
& \mathbf{B}_{\mathrm{qp}}^{\mathrm{oo}}=-\exp (-\mathrm{GB} \cdot \mathrm{T} / 2) /[1-\exp (-\mathrm{GB} \cdot \mathrm{T} / 2)]=\mathrm{A}_{\mathrm{qp}}^{\mathrm{oo}} \\
& \mathbf{B}_{\mathrm{qp}}^{\mathrm{oe}}=-\mathrm{Z}^{-1 / 2} \mathbf{A}_{\mathrm{qp}}^{\mathrm{oo}}
\end{aligned}
$$

The IAM matrix will be of size $12 \times 12$, since there are 6 nodes in the circuit, and each node can be considered separately during even and odd phases. But node 5 is grounded, so it can be discarded. During even phase, $\mathrm{a}^{\mathrm{e}}=1^{\mathrm{e}}$ and $\mathrm{p}^{\mathrm{e}}=\mathrm{z}^{\mathrm{e}}$, so two more columns and rows can be eliminated. Further, during odd phase, $\mathrm{a}^{\circ}$ is disconnected and $1^{\circ}$ and $2^{\circ}$ are grounded. Thus, the resulting matrix is

$\left[\begin{array}{cccccc}\mathrm{a}^{\mathrm{e}} & 1^{\mathrm{e}} & \mathrm{p}^{\mathrm{e}}-2^{\mathrm{e}} & \mathrm{q}^{\mathrm{e}} & \mathrm{P}^{\mathrm{o}} & \mathrm{q}^{\mathrm{o}} \\ \mathrm{p}^{\mathrm{e}} & \mathrm{C}_{1} & -\mathrm{C}_{1} & 0 & 0 & 0 \\ \mathrm{q}^{\mathrm{e}} & -\mathrm{C}_{1} & \mathrm{C}_{1}+\mathrm{C}_{2} & -\mathrm{C}_{2} & \mathrm{C}_{2} & -\mathrm{C}_{2} \\ \mathrm{p}^{\mathrm{o}} & 0 & -\mathrm{C}_{2} & \mathrm{C}_{2} & -\mathrm{C}_{2} & \mathrm{C}_{2} \\ \mathrm{q}^{\mathrm{o}} & 0 & \mathrm{C}_{2} & -\mathrm{C}_{2} & \mathrm{C}_{2} & -\mathrm{C}_{2} \\ & 0 & -\mathrm{C}_{2} & \mathrm{C}_{2} & -\mathrm{C}_{2} & \mathrm{C}_{2}\end{array}\right]$

where $C_{i}=-Z^{-1 / 2} C_{i}, i=1,2$. 
Inserting the constraints as given by the equations, one has the DAM $\left(\mathrm{Y}_{\mathrm{F}}\right)$ for the circuit as

$$
\left[\begin{array}{cccc} 
& \mathrm{q}^{\mathrm{e}} & \mathrm{q}^{\mathrm{e}} & \multicolumn{1}{c}{\mathrm{q}^{\mathrm{o}}} \\
\mathrm{a}^{\mathrm{e}} & \mathrm{C}_{1} & -\mathrm{A}_{\mathrm{ap}}^{\mathrm{ee}} \mathrm{C}_{1} & -\mathrm{A}_{\mathrm{qp}}^{\mathrm{eo}} \mathrm{C}_{1} \\
\mathrm{p}^{\mathrm{e}} & -\mathrm{C}_{1} & -\mathrm{C}_{2}+\mathrm{A}_{\mathrm{qp}}^{\mathrm{ee}} \times\left(\mathrm{C}_{1}+\mathrm{C}_{2}\right) & -\mathrm{C}_{2}+\mathrm{A}_{\mathrm{qp}}^{\mathrm{eo}} \times\left(\mathrm{C}_{1}+\mathrm{C}_{2}\right) \\
& & -\mathrm{A}_{\mathrm{qp}}^{\mathrm{oe}} \mathrm{C}_{2} & -\mathrm{A}_{\mathrm{qp}}^{\mathrm{oo}} \mathrm{C}_{2} \\
\mathrm{p}^{\mathrm{o}} & 0 & -\mathrm{C}_{2}+\mathrm{A}_{\mathrm{qp}}^{\mathrm{ee}} \mathrm{C}_{2} & -\mathrm{C}_{2}+\mathrm{A}_{\mathrm{qp}}^{\mathrm{eo}} \mathrm{C}_{2} \\
& & \mathrm{~A}_{\mathrm{qp}}^{\mathrm{oe}} \mathrm{C}_{2} & \mathrm{~A}_{\mathrm{qp}}^{\mathrm{oo}} \mathrm{C}_{2}
\end{array}\right]
$$

$\mathrm{Y}_{\mathrm{F}}$ can be manipulated to obtain the transfer function $\mathrm{V}_{\mathrm{q}}^{\mathrm{e}} / \mathrm{V}_{\mathrm{a}}^{\mathrm{e}}=\Delta_{12} / \Delta_{11}$, where $\Delta_{\mathrm{ij}}$ is the cofactor of $\mathrm{Y}_{\mathrm{F}}$ corresponding to the ith row and jth column. On calculating the cofactor, one obtains.

$$
\begin{aligned}
& \frac{V_{q}^{e}(z)}{V_{a}^{e}(z)}=-\frac{C_{1}}{C_{2}} \frac{1-e^{k_{1}}+Z^{-1 / 2} \mathrm{Ke}^{-k_{1}}\left(1-e^{-k_{2}}\right)}{\left(1-Z^{-1}\right)\left(1-\mathrm{K} \mathrm{z}^{-1} e^{\left(k_{1}+k_{2}\right)}\right)} \\
& K_{1}=\text { GB. } \frac{C_{2}}{C_{1}+C_{2}} T / 2, K_{2}=\text { GB. T/2, K }=\frac{C_{2}}{C_{1}+C_{2}}
\end{aligned}
$$

\section{COMPENSATION FOR PARAMETER DEVIATION}

The finite gain-bandwidth products of OAs offset the frequency response of finite gain amplifiers (FGA), and consequently, of the circuits that use them. For example, the realized pole $\mathrm{Q}$-factor $\left(\mathrm{Q}_{\mathrm{pk}}\right)$ and pole frequency $\left(\omega_{\mathrm{pk}}\right)$ of an active RCfilter may deviate drastically from the designed values; sometimes even leading to instability. In oscillators, the actual frequency of oscillation can be widely different from the desired one. Thus, in order to avoid the undesirable effect of the GBs, the application of these filters and oscillators is restricted to low frequencies, typically of the order of a few $\mathrm{KHz}$ only.

One way to minimize this problem is to provide passive or active compensation in the circuits that use these FGA's.

There are several well known passive compensation techniques that make use of additional passive components to introduce a controlled amount of phase lead that cancels the excess phase lag due to the amplifiers limited bandwidth. The main difficulty with passive compensation is that the additional compensating elements must be individually tailored to the given $\mathrm{OA}$ and adjusted at specific ambient conditions of temperature and power supply voltage.

With the introduction of low-cost dual and quad OAs having closely matched characteristics that track with changes in temperature and voltage, it becomes feasible to consider an active compensation method whereby OA in a circuit provides compensation for other $\mathrm{OA}$ in the same circuit.

\section{OP AMP INTEGRATORS WITH REDUCED EFFECT OF GB}

A Deboo Integrator uses grounded capacitor and is a non-inverting type. Although its Q-factor is higher than that of the Miller-Integrator, the Deboo Integrator is 
quite sensitive to resistor ratio matching and therefore, has limited practical use $[9,10]$.

The feedback compensation technique is employed in the circuit of Fig. 1.9(a) to realize an inverting integrator having an ultra high $Q$-factor, namely $Q \cong-|A|^{3}$. This improvement of many orders of magnitude is obtained assuming OA matching.

Another form of active compensation is the feed-forward compensation technique employed in the non-inverting integrator of Fig. 1.9(b). This is modified Miller inverter integrator

In another modification, both the feed forward and feedback compensation techniques are combined to obtain the modified high-Q integrators. This has ultrahigh $Q$-factor; $Q_{2} \cong-|A|^{3}$

\section{BIQUADRATIC FILTER SECTIONS}

The above better designs of integrators can directly be adopted for designing a biquadratic filter section as a two-integrator loop. Figure 1.4(a) shows a blockdiagram of the loop consisting of two integrators; one inverting and one noninverting. If the integrators ae not ideal but have finite $Q$-factors $Q_{1}$ and $Q_{2}$, the realized pole $Q$ is given by

$$
\mathrm{Q}_{\mathrm{k}}=\frac{1}{\left[1 / \mathrm{Q}+1 / \mathrm{Q}_{1}+1 / \mathrm{Q}_{2}\right]}
$$

To implement the two-integrator biquad, different combination of inverting and non-inverting integrators can be selected. The final biquad circuit in Figure 1.10 uses the high- $Q$ circuit $\left(Q=-|A|^{3}\right)$ for two inverting integrators. The result is a pole $Q$ that is closer to the design value than that obtained in any other circuit.

The introduction of a leading phase to cancel the lagging phase introduced by the finite bandwidth should extend the point of which $Q_{p}$ enhancement occurs. The leading phase can be introduced by placing a small capacitor across a feedback resistor or some suitable resistor $R_{2}$ or $R_{3}$. The value of the required capacitor is given by

$C_{c}=\frac{4}{A_{o} \omega_{o} R_{3}}$

\section{Offset Effect Reduction}

The input offset voltage results in an offset voltage at the output equal to $V_{d c}$ times the closed loop gain. The polarity of $V_{d c}$ is random and is typically less than 10 $\mathrm{mV}$.

The two bias currents are nearly equal except for a small difference or offset current $I_{0}$. The non-inverting input bias current has no effect. To minimize the effect of $I_{o}$, a high value of Req should be avoided. A more commonly used approach involves introducing a resistor having the value Req between the non- 


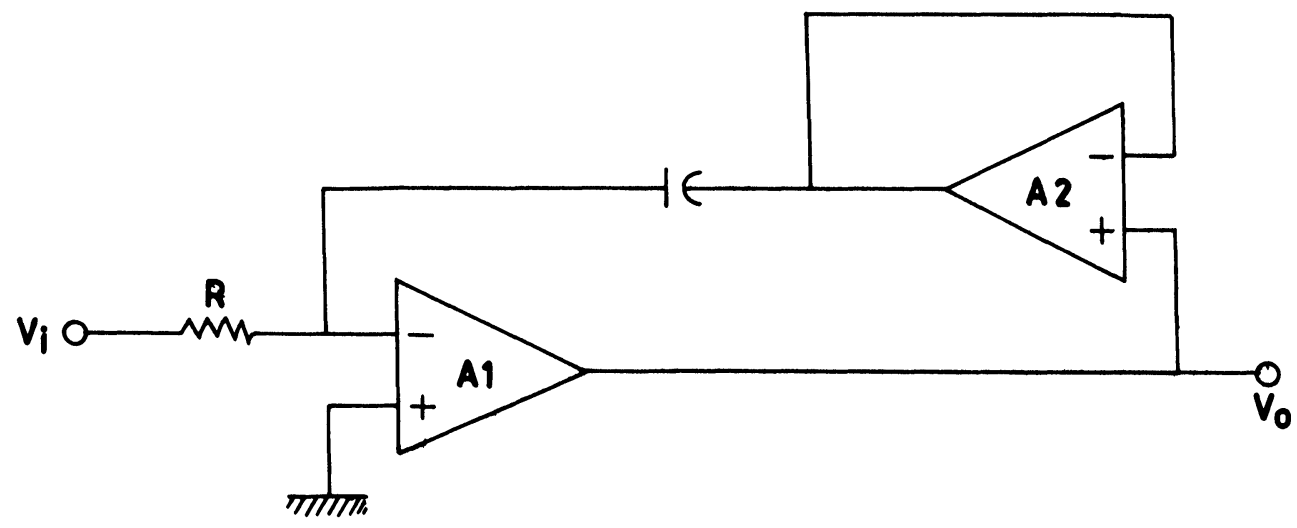

FIGURE 1.9(a) High Q (Inverting)

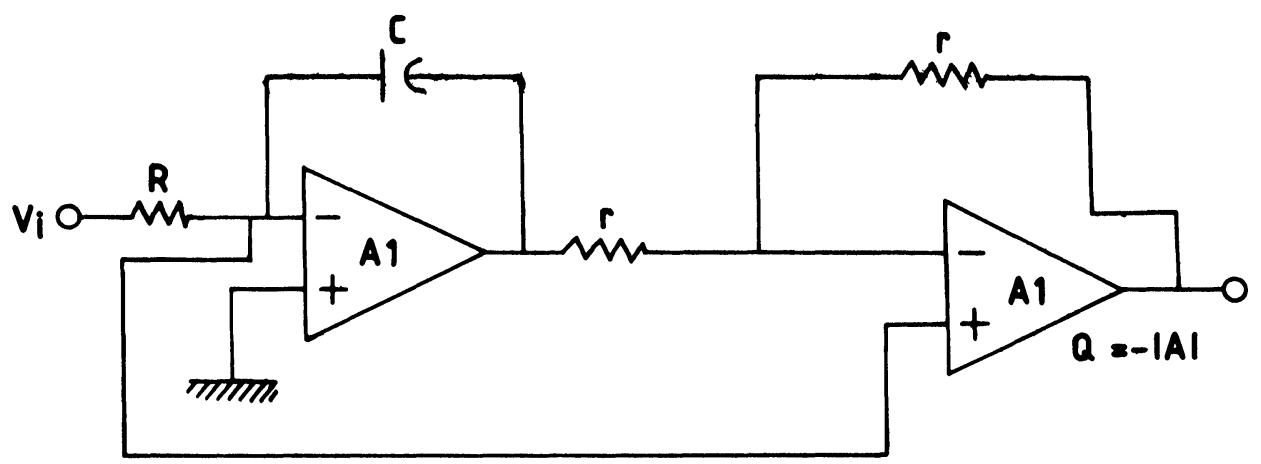

FIGURE 1.9(b) Modified Miller-Inverter

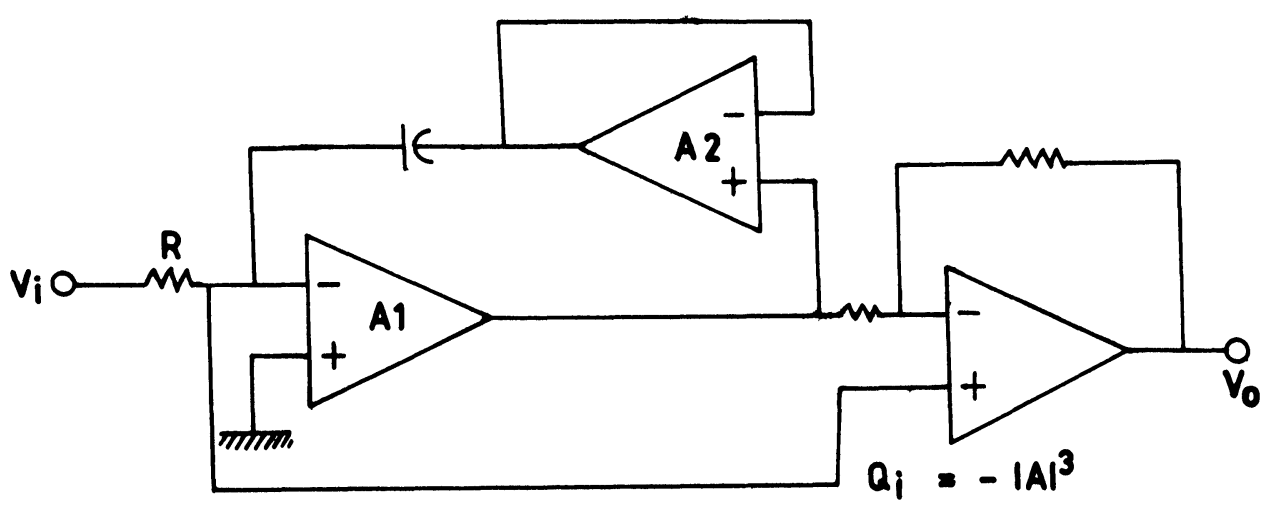

FIGURE 1.9(c) 


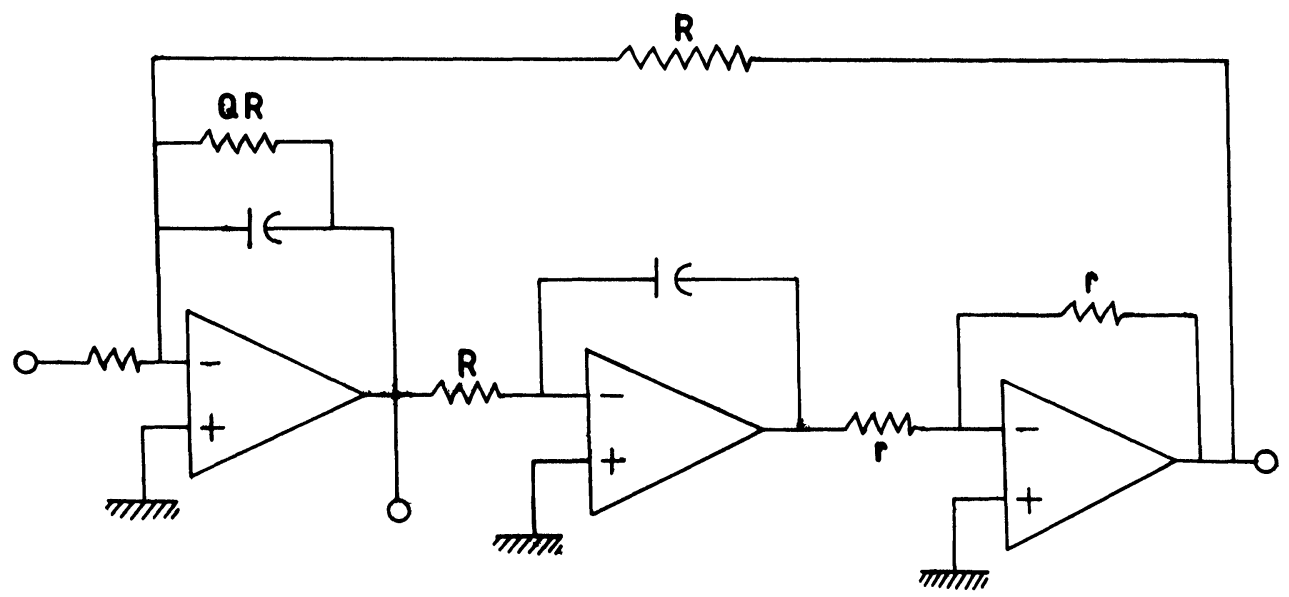

FIGURE 1.10 Biquad using Miller Inverter Integrator

inverting input and ground. This has no effect on the overall gain. However, a DC offset voltage $I_{b}$ Req is introduced at the non-inverting input. Since the amplifer is a differential device, the net error voltage due to the offset current is (Ia-Ib) Req or $I_{o}$ Req. Since $I_{a}$ and $I_{b}$ are typically $80 \mathrm{nA}$ and the offset current $I_{o}$ is in the range of $20 \mathrm{nA}$, a $4: 1$ reduction is obtained.

\section{OFFSET IN SWITCHED CAPACITOR FILTERS}

DC offset is an important effect of OAs used in SC circuits. A scheme was proposed for eliminating this effect in SC circuits. Its basic principle is that the capacitors of the offset-free stage are never disconnected from the inverting input terminal of the OA and, hence, the input-referred DC offset voltage $V_{d c}$ cannot affect the charge transfers. To make this possible, the OA output is short-circuited in every half clock cycle to the inverting input terminal.

As a result, the OA output voltage $V_{o}$ must switch back and forth between the desired output signal and $\mathrm{V}_{\mathrm{dc}}$ every half period. Since the size of the signal may be several volts, while $V_{d c}$ is typically $10-20 \mathrm{mV}$, the slew rate of the OA must be large. The offset voltage is modeled as a voltage-source at the non-inverting input terminal. Charge conservation equations are

$\mathrm{C}_{1} \mathrm{~V}_{\mathrm{dc}}+\mathrm{C}_{2}\left[\mathrm{~V}_{\mathrm{dc}}-\mathrm{V}_{2}(\mathrm{t})\right]=\mathrm{C}_{1}\left[\mathrm{~V}_{\mathrm{dc}}-\mathrm{V}_{1}(\mathrm{t}-\mathrm{T} / 2)\right]+\mathrm{C}_{2}\left[\mathrm{~V}_{\mathrm{dc}}-\mathrm{V}_{3}(\mathrm{t}-\mathrm{T} / 2)\right]$

$V_{3}(t-T)=V_{2}(t-T)$

Then, $\mathrm{V}_{2}(\mathrm{t})=\mathrm{V}_{2}(\mathrm{t}-\mathrm{T})+\mathrm{C}_{1} / \mathrm{C}_{2}(\mathrm{t}-\mathrm{T} / 2)$

Thus, the relationship between the input and output signal is not dependent on the offset voltage. 
Another offset-free inverting integrator that does not require such high slew rates from the OA is shown in Fig. 2.0

Nodal analysis can be used to show that the input/output relations of the circuit are:

$\mathrm{V}_{\mathrm{o}}(\mathrm{t})=\mathrm{V}_{\mathrm{o}}(\mathrm{t}-\mathrm{T} / 2)-\left(\mathrm{c}_{1} / \mathrm{C}_{2}\right) \mathrm{V}_{\mathrm{i}}(\mathrm{t})$ when $\phi_{1}=1$

$\mathrm{V}_{\mathrm{o}}(\mathrm{t}+\mathrm{T} / 2)=\mathrm{V}_{\mathrm{o}}(\mathrm{t})+\mathrm{V}_{\mathrm{dc}} \quad$ when $\phi_{2}=1$

The circuit performs as an offset-free integrator when $\phi_{1}$ is high and the output changes by only $V_{d c}$ when $\phi_{2}$ goes high. Physically, $C_{3}$ enables $C_{1}$ to discharge to $-V_{d c}$ during $\phi_{2}=1 . C_{3}$ is precharged earlier to $V_{o}(t)-V_{i}(t)$ to be able to absorb charge from $C_{1}$ without a significant change in $V_{o}$.

\section{Reduction of Slew-rate Effect}

No suitable method has been suggested to overcome the effect of slew-rate. However, to reduce this effect, the following methods are suggested.

1. To use the OA with a high-slew rate so that limitations of low slew rate could not be imposed. Such OA may be of BJT type or CMOS type, etc.

2. Input to the filter can be clipped so as to keep the output slope of the OA less than the slew rate. While this method allows larger signal levels at lower frequencies than amplitude limiting, it creates its own distortion in the form of higher harmonics.

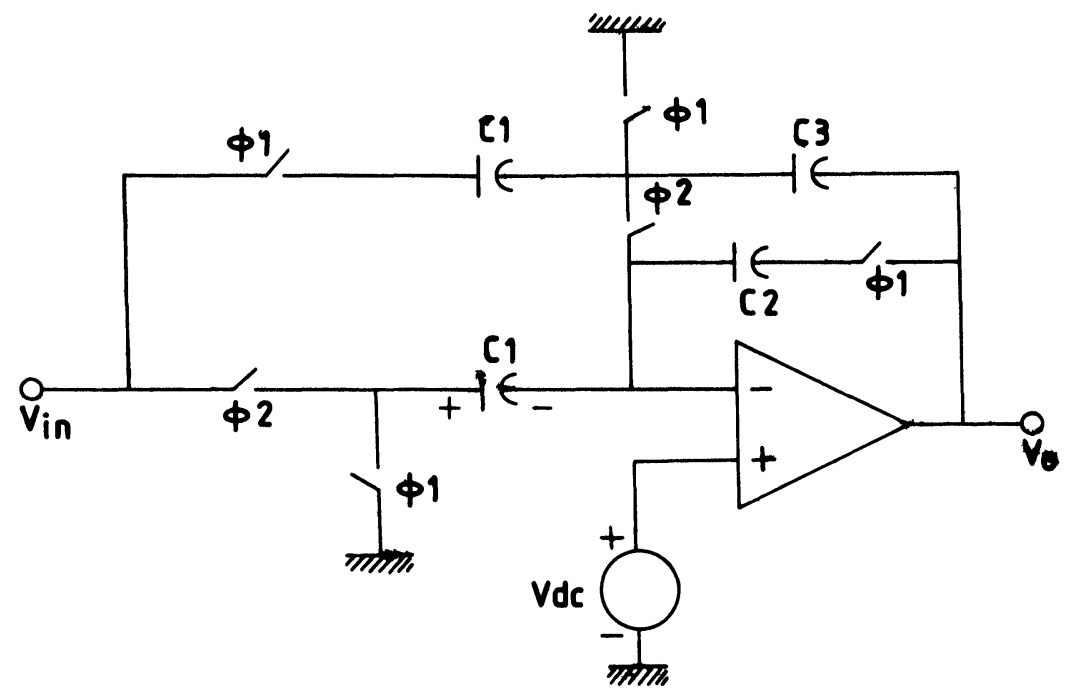

FIGURE 2.0 Offsetfree Non-inverting Integrator 


\section{CONCLUSION}

From the study of imperfections in OAs, it is seen that these imperfections lead to performance degradation in active filters. All + ve feedback filters have their value of $Q_{p}$ increased with a decrease in $A_{o} / \omega_{o} / \omega_{p}$. In addition, the variation in $Q$ is much steeper for the state-variable filters than for + ve feedback filters.

Values of $Q$ and $\omega_{p}$ to be realized also affect the deviations in these values (Fig. 3.1 and 3.2). But the effect of non-idealities in gain and bandwidth is to increase

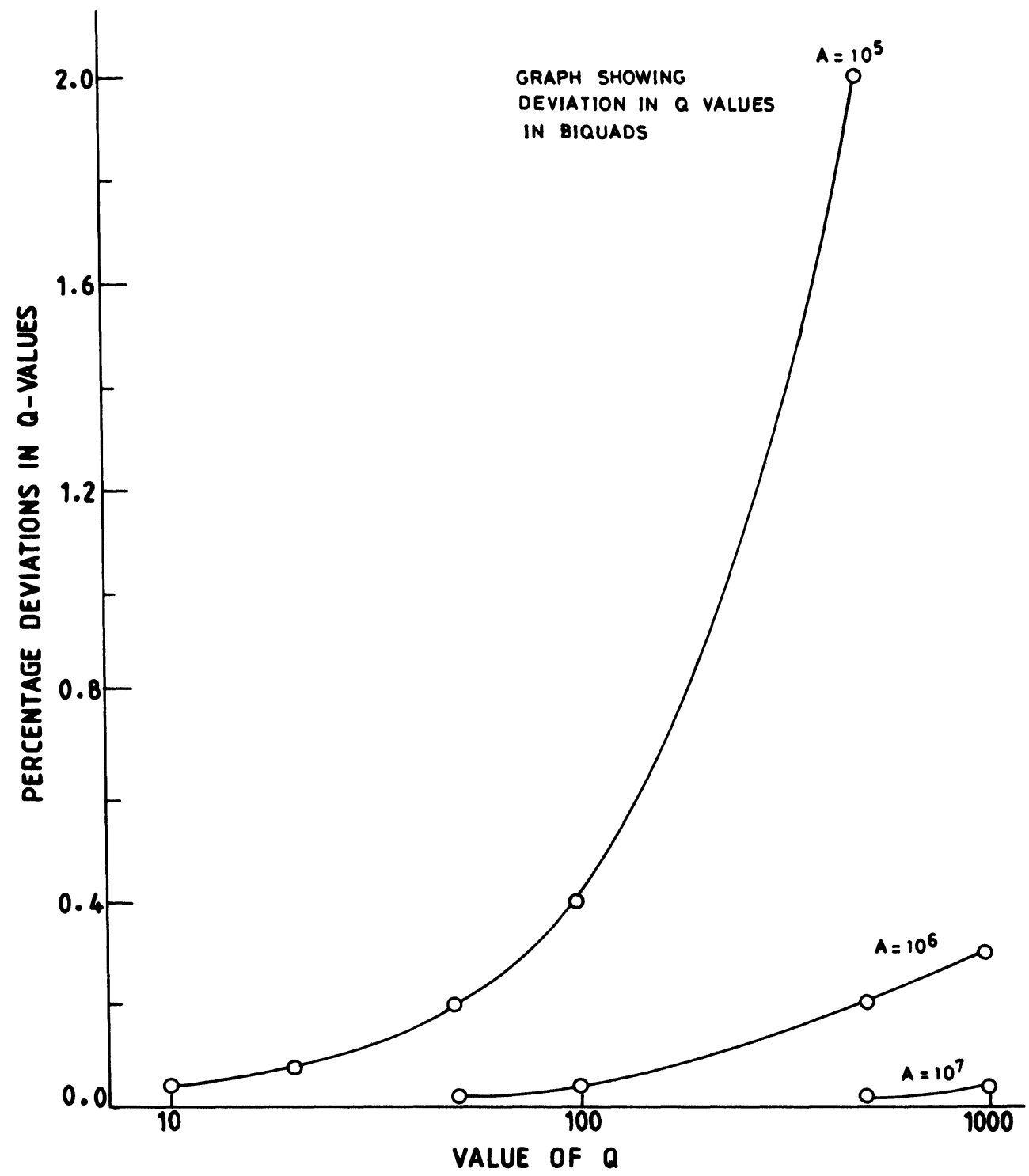

FIGURE 3.0 


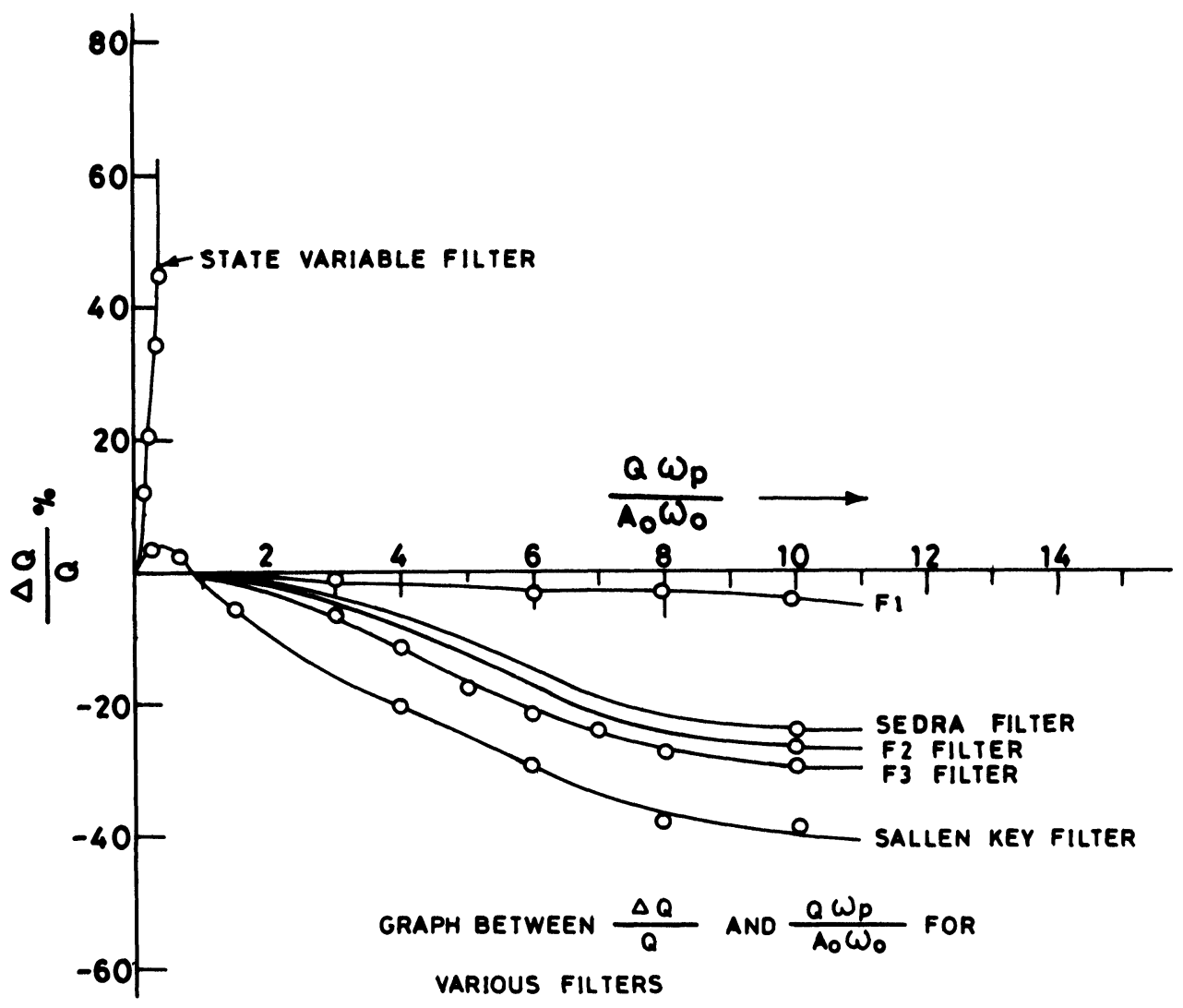

FIGURE 3.1

the value of $Q$. Finite bandwidth, i.e., pole at $\omega_{0}$, introduces extra phase lag and degrades the filter performance.

The effect of slew rate is to induce distortion at the output when input voltage level is high. DC offset voltage induces an extra voltage at the output, which is equal to close-loop gain multiplied by input offset voltage.

There is one big advantage of finite gain imperfection. Based on this non-ideal property of OP AMPs, active $\mathrm{R}$ and active $\mathrm{C}$ filters are being developed. Various compensation techniques have been described (active and passive). The concept of $\mathbf{Q}$ factor of integrators have been introduced that must be ideally infinite. By using active compensation techniques, a $\mathrm{Q}$-factor of as high as $\mathrm{A}^{3}$ can be obtained, where $A$ is the open loop gain of OA. Distortion at output and deviation in frequency response from that of an ideal OP AMP can be predicted. These can be taken into consideration in the design process itself, and better filters can be constructed.

\section{REFERENCES}

1. A. Budak and Petrela. "Frequency Limitations of Active Filter using Operational Amplifier," IEEE Trans. on Circuit Theory, pp. 322-328, July 1972. 
2. P.O. Brackett and A.S. Sedra, "Active compensation for High-frequency effects in op-amp circuits with applications to Active RC Filters," IEEE Trans. on Circuits and Systems, pp. 68-72, February 1976.

3. Allen, Phillip E., "A model for slew-induced distortion in Single-Amplifier active filters," IEEE Trans. on Circuits and Systems, pp. 565-572, August 1978.

4. Temes, G.C., "Finite amplifier gain and bandwidth effects in Switched-Capacitor Filters," IEEE Journal of Solid State Circuits, pp. 358-361, June 1980.

5. Edgar Sanchez-Sinencio, et al, "Effects of finite operational amplifier GB product on a SC amplifier," Electronics Letters, Vol. 17, No. 14, pp. 509-510, 9th July, 1981.

6. K. Martin and A.S. Sedra, "Effects of the op amp finite gain and bandwidth on the performance of SC filters," IEEE Trans. on CAS, pp. 822-829, August 1981.

7. Randall L. Geiger, et al, "Operational amplifier GB product effects on the performance of SC networks," IEEE Trans. on CAS, pp. 96-106, February 1982.

8. Peter Bowron and F.W. Stephenson, "Active Filters for Communications and Instrumentation," McGraw Hill Ltd.

9. George S. Moschytz, "Reducing nonideal op-amp effects in active filters by minimizing the gainsensitivity product (GSP)," IEEE Trans. on CAS, August 1977.

10. Edgar Sanchez-Sinencio, "GB Effects on SC filters including a quasi Optimal Topology," IEEE Circuits and Systems Magazine, December 1983. 

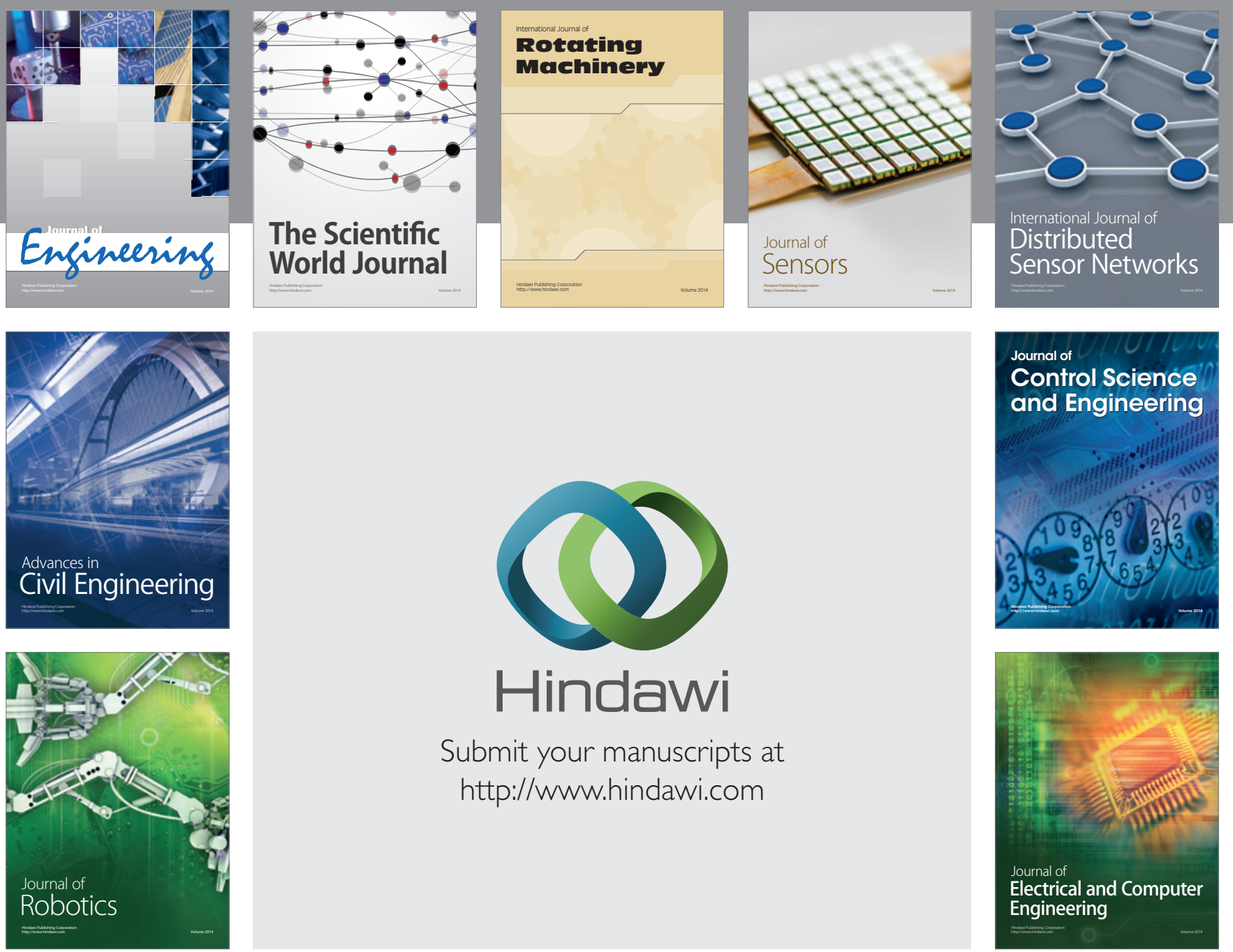

Submit your manuscripts at

http://www.hindawi.com
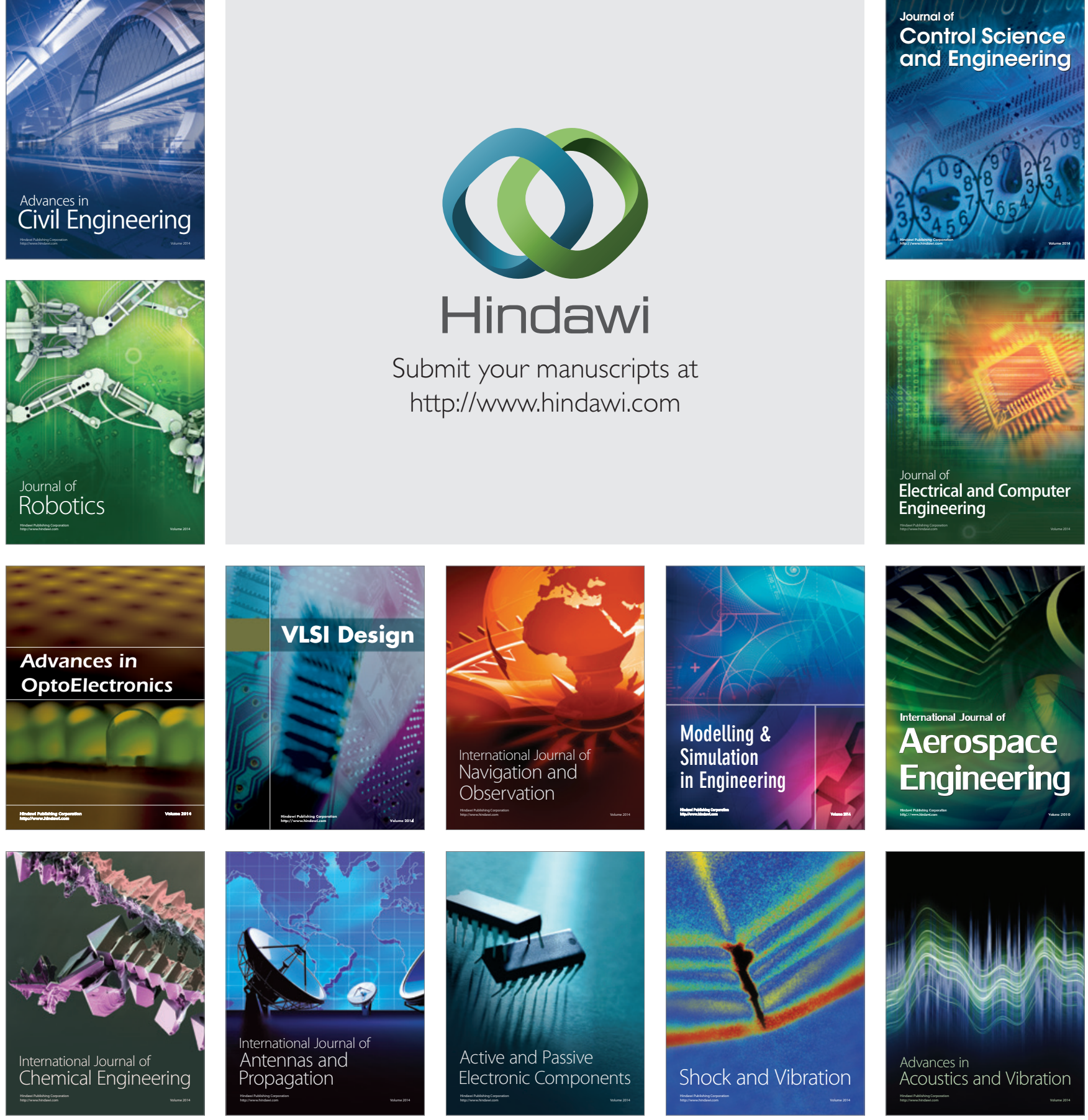